\title{
Insulator-to-Proton-Conductor Transition in a Dense Metal-Organic Framework
}

\author{
Satoshi Tominaka, ${ }^{* \dagger} \dagger$ François-Xavier Coudert, ${ }^{\S}$ Thang D. Dao ${ }^{\ddagger}$ Tadaaki Nagao, \\ and Anthony K. Cheetham* ${ }^{\dagger}$ \\ ${ }^{\dagger}$ Department of Materials Science and Metallurgy, University of Cambridge, Cambridge CB3 OFS, United Kingdom \\ ${ }^{\ddagger}$ International Center for Materials Nanoarchitectonics, National Institute for Materials Science, Ibaraki 305-0044, Japan \\ ${ }^{\S}$ PSL Research University, Chimie ParisTech-CNRS, Institut de Recherche de Chimie Paris, 75005 Paris, France
}

\section{Supporting Information}

ABSTRACT: Metal-organic frameworks (MOFs) are prone to exhibit phase transitions under stimuli such as changes in pressure, temperature, or gas sorption because of their flexible and responsive structures. Here we report that a dense MOF, $\left(\left(\mathrm{CH}_{3}\right)_{2} \mathrm{NH}_{2}\right)_{2}\left[\mathrm{Li}_{2} \mathrm{Zr}\left(\mathrm{C}_{2} \mathrm{O}_{4}\right)_{4}\right]$, exhibits an abrupt increase in proton conductivity from $<10^{-9}$ to $3.9 \times 10^{-5} \mathrm{~S} / \mathrm{cm}$ at $17{ }^{\circ} \mathrm{C}$ (activation energy, $0.64 \mathrm{eV}$ ) upon exposure to humidity. The conductivities were determined using single crystals, and the structures were analyzed by X-ray diffraction and X-ray pair distribution function analysis. The initial anhydrous structure transforms to another dense structure via topotactic hydration $\left(\mathrm{H}_{2} \mathrm{O} / \mathrm{Zr}=0.5\right)$, wherein one-fourth of the $\mathrm{Li}$ ions are irreversibly rearranged and coordinated by water molecules. This structure further transforms into a third crystalline structure by water uptake $\left(\mathrm{H}_{2} \mathrm{O} / \mathrm{Zr}=4.0\right)$. The abrupt increase in conductivity is reversible and is associated with the latter reversible structure transformation. The $\mathrm{H}_{2} \mathrm{O}$ molecules coordinated to $\mathrm{Li}$ ions, which are formed in the first step of the transformation, are considered to be the proton source, and the absorbed water molecules, which are formed in the second step, are considered to be proton carriers.

$\mathrm{P}$ hase transitions in solid-state materials lead to nonlinear changes in properties that can play key roles in the development of innovative, functional materials. Nanoporous metal-organic frameworks (MOFs), composed of metal cations and anionic organic linkers, ${ }^{1}$ exhibit an unusual range of phase transitions under relatively mild conditions because of their flexible and responsive structures. For example, both high-spin/ low-spin ${ }^{2}$ and open-pore/closed-pore transitions have been observed as functions of temperature and guest loading. ${ }^{3}$ In the case of dense $\mathrm{MOFs}^{4}{ }^{4}$ a reversible, pressure-induced transition with extensive bond rearrangements has recently been described. ${ }^{5}$ Here we report that a dense anhydrous MOF, $(\mathrm{dma})_{2}\left[\mathrm{Li}_{2} \mathrm{Zr}(\text { ox })_{4}\right]$ (I, with dma = dimethylammonium, ox $=$ oxalate), transforms to another dense structure, phase II, via topotactic hydration. Phase II exhibits an abrupt increase in proton conductivity by at least 4 orders of magnitude upon further exposure to humidity, transforming the structure to another crystalline phase, III. When the humidity is reduced, the structure does not return to phase I, but only to phase II. In general, humidity-induced phase transitions are rare because changes in humidity are normally insufficient to induce a change in the crystal structure of a dense material. To our knowledge, the only previous examples concern disorder/order transitions in organic materials, ${ }^{6}$ crystal structure transformations in salts by hydration (e.g., iron sulfate), ${ }^{7}$ and structural transformations in microporous MOFs. ${ }^{8}$

Figure la shows humidity-dependent proton conductivities measured by the single-crystal impedance method (Supporting Information, Figure S1). ${ }^{9,10}$ The as-synthesized crystal $\mathbf{I}$ is insulating up to $50 \%$ relative humidity $(\mathrm{RH})$, with a conductivity lower than the detection limit of the system $\left(\sim 5 \times 10^{-9} \mathrm{~S} / \mathrm{cm}\right)$. However, increasing the $\mathrm{RH}$ to $67 \%$ results in an abrupt transition to a state with a conductivity of $3.9 \times 10^{-5} \mathrm{~S} / \mathrm{cm}$ at 17 ${ }^{\circ} \mathrm{C}$; this, in fact, is phase III. With decreasing humidity, the conductivity decreases slightly but remain high, at $1.6 \times 10^{-5} \mathrm{~S} /$ $\mathrm{cm}$, down to $\mathrm{RH}=33 \%$. The high conductivities are stable overnight and comparable to those of classic solid-state materials $\left(10^{-3}-10^{-8} \mathrm{~S} / \mathrm{cm}\right)^{11}$ as well as MOF-based materials. ${ }^{9,12} \mathrm{On}$ further lowering the $\mathrm{RH}$ to $25 \%$, the material becomes insulating again due to the formation of II, but the high conductivity can be recovered by increasing the $\mathrm{RH}$ to $67 \%$ (Figure S1). These single-crystal measurements using microelectrodes themselves indicate the potential application of this material as a conductivity-switching device in response to humidity changes, as reported for electronic conductivity ${ }^{13}$ and magnetic properties. $^{14}$

By measuring the temperature-dependent conductivities in the range of $20-36{ }^{\circ} \mathrm{C}$ at a constant $\mathrm{RH}=61 \%$ (Figure S2), we obtained the Arrhenius plots (Figure 1b). The activation energy $E_{\mathrm{a}}$ for the conduction is $0.64 \mathrm{eV}$, and the pre-exponential factor $\sigma_{0}$ is $3.8 \times 10^{8} \mathrm{~S} / \mathrm{cm} \mathrm{K}$. The activation energy is similar to those of anhydrous inorganic crystals (e.g., $\left.\mathrm{KH}_{2} \mathrm{PO}_{4}, 0.60 \mathrm{eV}\right)^{9,15}$ and a layered MOF hydrate $\left(\left(\mathrm{NH}_{4}\right)_{2}(\mathrm{adp})\left[\mathrm{Zn}_{2}(\mathrm{ox})_{3}\right] \cdot 3 \mathrm{H}_{2} \mathrm{O}(\mathrm{adp}=\right.$ adipic acid), $0.63 \mathrm{eV}),{ }^{16}$ and slightly larger than that of a layered inorganic hydrate $\left(\left[\mathrm{HUO}_{2} \mathrm{PO}_{4}\right] \cdot 4 \mathrm{H}_{2} \mathrm{O}, 0.38 \mathrm{eV}\right){ }^{9,15}$ This high activation energy (cf. aqueous solution, $<0.1 \mathrm{eV}$; gels and polymer electrolytes, $<0.3 \mathrm{eV}),{ }^{9}$ as well as the small humidity dependence in the $\mathrm{RH}$ range $67-33 \%$, suggests that protons do not transport through free water molecules adsorbed on the

Received: November 30, 2014

Published: May 4, 2015 

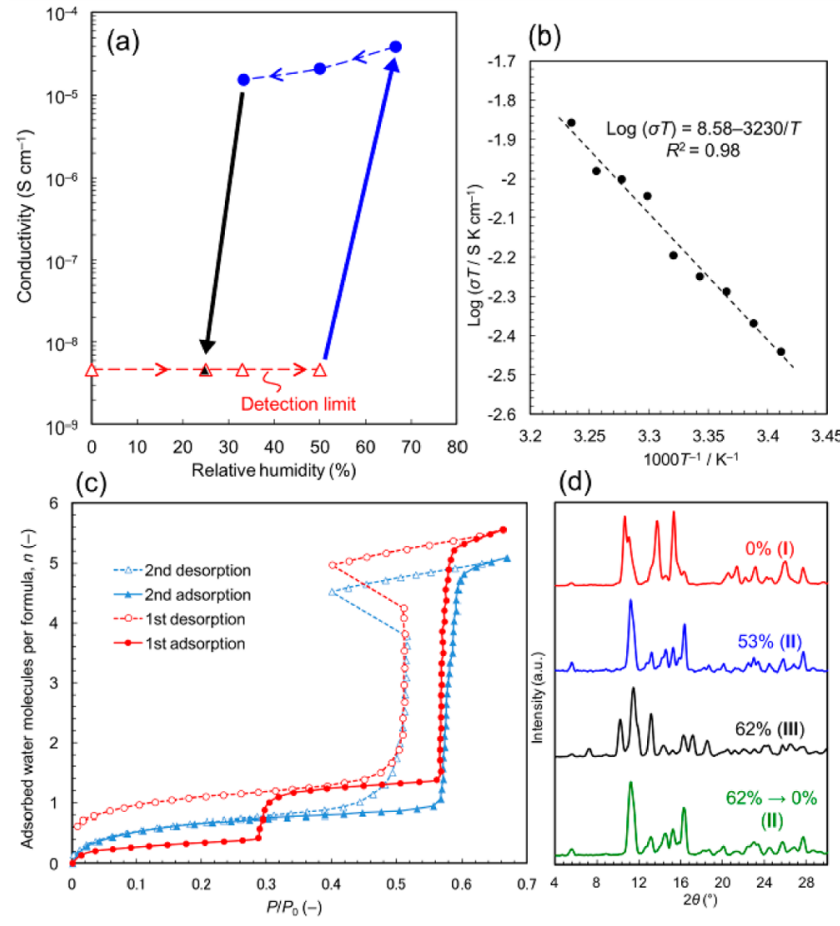

Figure 1. Abrupt increase in proton conductivity with relative humidity. (a) Humidity dependence of proton conductivity data obtained by single-crystal impedance measurements at $17{ }^{\circ} \mathrm{C}$. The arrows show the direction of $\mathrm{RH}$ change from $0 \%$ to $67 \%$, and then to $25 \%$. Triangles indicate data below the detection limit (100 G $\Omega$ ). The data were obtained along the $c$ axis of the parent crystal. (b) Arrhenius plots of the temperature dependence of conductivity at $\mathrm{RH}=61 \%$ (phase III). (c) Water adsorption/desorption isotherms at $25{ }^{\circ} \mathrm{C}$. The vertical axis shows the number of adsorbed water molecules per $(\mathrm{dma})_{2}\left[\mathrm{Li}_{2} \mathrm{Zr}(\mathrm{ox})_{4}\right]$ unit. (d) PXRD patterns collected under humidity control. The samples were sealed in glass capillaries in dry air $(\mathrm{RH}=0 \%$, as-synthesized phase I) and in humidified nitrogen at $\mathrm{RH}=53 \%$ (phase II), 62\% (phase III), and $0 \%$ after holding at $62 \%$ (phase II).

surface but through the framework and/or micropores. ${ }^{9}$ Since the conductivity depends on humidity, the mobile ions are judged to be protons, not other ions such as $\mathrm{Li}^{+}$.

To understand the role of humidity, ${ }^{17-19}$ water vapor adsorption/desorption isotherms (Figures 1c and S3) were measured at $25{ }^{\circ} \mathrm{C}$. The adsorption isotherm of the first cycle shows two-step adsorption. The first step $\left(P / P_{0}=0.3\right.$; number of $\mathrm{H}_{2} \mathrm{O}$ molecules per $\left.(\mathrm{dma})_{2}\left[\mathrm{Li}_{2} \mathrm{Zr}(\mathrm{ox})_{4}\right], n=0.72\right)$ is associated with a structural transformation from $I$ to another crystalline phase, II, as shown in the powder X-ray diffraction (PXRD) patterns of the samples sealed under humidity control (Figure $1 d)$. The second step $\left(P / P_{0}=0.58, n=4.0\right)$ is associated with a further transformation to another crystalline phase, III, as shown in Figure 1d, and accounts for the abrupt increase of proton conductivity. The desorption isotherm shows that this secondstep adsorption is reversible with hysteresis, and the humidity jump from $P / P_{0}=0.40$ to 0.51 can be ascribed to the rapid release of water vapor from the material. On the other hand, the transition from I to II is irreversible $\left(n=0.62\right.$ at $P / P_{0}=7.2 \times$ $10^{-3}$ ). In the second cycle of adsorption measurements (where $n$ was redefined to be 0 at $P / P_{0}<4.2 \times 10^{-4}$ ), the material gradually adsorbed water to $P / P_{0}=0.2(n=0.55)$ and then showed the same uptake around $P / P_{0}=0.58(n=4.0)$ when II transformed back to III. The abrupt transformation might be accounted for by a gate effect occurring in II, $^{20}$ whereby the most flexible molecules (i.e., dma cations) are considered to open channels for water diffusion toward the center. Alternatively, such abrupt adsorption/desorption isotherms with hysteresis are typical for crystalline hydrates where hydrophilicity is different at different hydration levels. $^{21}$

Single crystals of the parent, insulating phase I were synthesized by solvothermal reaction between lithium nitrate, zirconium butoxide, and oxalic acid in dimethylformamide. The crystals are colorless prisms, adopting the monoclinic $12 / a$ space group $[a=16.1266(5), b=16.6648(6)$, and $c=15.4756(4) \AA, \beta$ $=91.161(3)^{\circ}$ at $302 \mathrm{~K}$; Table S1]. I forms a $3-\mathrm{D}$ anionic framework composed of tetrahedrally coordinated $\mathrm{Li}^{+}$and dodecahedrally coordinated $\mathrm{Zr}^{4+}$ cations connected by oxalate anions, $\mathrm{C}_{2} \mathrm{O}_{4}{ }^{2-}$ :ox (Figure $2 \mathrm{a}-\mathrm{c}$ ). As is common in anionic MOFs, ${ }^{22}$ the negative framework charge $(-2 / \mathrm{Zr})$ is neutralized by the presence of an amine, in this case dma cations; $\left(\mathrm{CH}_{3}\right)_{2} \mathrm{NH}_{2}^{+}$ions are located between $\mathrm{ZrO}_{8}$ polyhedra, and the square channels are filled with their methyl groups (Figures $2 \mathrm{c}$ and S4). The overall composition of $\mathrm{I}$ is $(\mathrm{dma})_{2}\left[\mathrm{Li}_{2} \mathrm{Zr}(\mathrm{ox})_{4}\right]$. The chemical compositions were determined by CHN elemental analysis at the Department of Chemistry, University of Cambridge (found, calcd in \%): C (26.05, 26.23), H (2.89, $2.91), \mathrm{N}(4.98,5.10)$. There is no porosity in $\mathrm{I}$ (solvent accessible volume, $\mathrm{SAV}=0 \%)$.

The structure of phase II was determined by single-crystal diffraction, and its composition is $(\mathrm{dma})_{2}\left[\mathrm{Li}_{2}\left(\mathrm{H}_{2} \mathrm{O}\right)_{0.5} \mathrm{Zr}(\mathrm{ox})_{4}\right]$. II crystallizes in the triclinic space group $P 1[a=8.5302(6), b=$ 8.5902(6), and $c=16.1582(12) \AA, \alpha=89.309(6), \beta=78.004(6)$, and $\gamma=68.812(6)^{\circ}$ at $299 \mathrm{~K}$; Table S1]. The reaction of I to form II adds a single water molecule to one in four of the lithium cations (Figures $2 \mathrm{f}$ and $\mathrm{S} 5$ ), increasing its coordination number from 4 to 5 . For structure determination of II, we cut a small region from a single crystal of $\mathbf{I}$ that had been hydrated, thereby obtaining a single-crystalline domain; this is because the transformation of I to II leads to the formation of twin domains. Like I, the structure of II is dense (SAV $=3 \%, 36 \AA^{3}$ for an isolated void in the unit cell; Figure S6), ${ }^{23}$ but the water vapor isotherms indicate that these isolated voids are mostly accessible and can be filled with water molecules due to the flexible framework and/or the motion of dma molecules. ${ }^{24}$ The composition of II calculated from the crystallographic data corresponds to the $\mathrm{CHN}$ elemental analyses (found, calcd in \%): $\mathrm{C}(25.66,25.81), \mathrm{H}(3.19,3.04), \mathrm{N}(5.06,5.02)$, which also confirms that the phase transformation does not change the N/C ratio, so there is no replacement of dma by water. The amount of coordinated water was confirmed by thermogravimetric analysis (Figure S7), which shows an endothermic loss at $\sim 100{ }^{\circ} \mathrm{C}$ (obsd $1.5 \mathrm{wt} \%$, calcd $1.6 \mathrm{wt} \%)$.

The transformation of I to II can be understood by careful comparison of their crystal structures. Both structures have square, 1-D channels formed by $\left[\mathrm{Zr}(\mathrm{ox})_{4}\right]^{4-}$ anions, connected by the $\mathrm{Li}^{+}$cations (Figure 2a,e). The channels are filled by dma cations, and no significant micropores exist, as discussed above. The structure of $\mathrm{I}$ adopts an $\mathrm{I}^{0} \mathrm{O}^{3}$ network according to the nomenclature of Cheetham et al.; ${ }^{25}$ there is no extended inorganic connectivity. However, on hydration, $\mathrm{Li}_{\mathrm{B}}$ moves laterally and binds the water molecule (Figure $2 b$ ) to form an inorganic chain of edge-sharing $\mathrm{LiO}_{5}$ units (Figure 2f,g); thus, the connectivity of II becomes $\mathrm{I}^{1} \mathrm{O}^{2}$. At the same time, half of the $\left[\mathrm{Zr}(\mathrm{ox})_{4}\right]^{4-}$ anions, $\mathrm{Zr}_{\mathrm{A}}$ and $\mathrm{Zr}_{\mathrm{C}}$ (Figure $2 \mathrm{~b}$ ), rotate such that the structure retains the square channels. The arrangements of $\mathrm{Zr}^{4+}$ cations can be regarded as constant during this transformation, and the unit cell relationships are illustrated in Figure $2 \mathrm{~d}, \mathrm{~h}$. The 

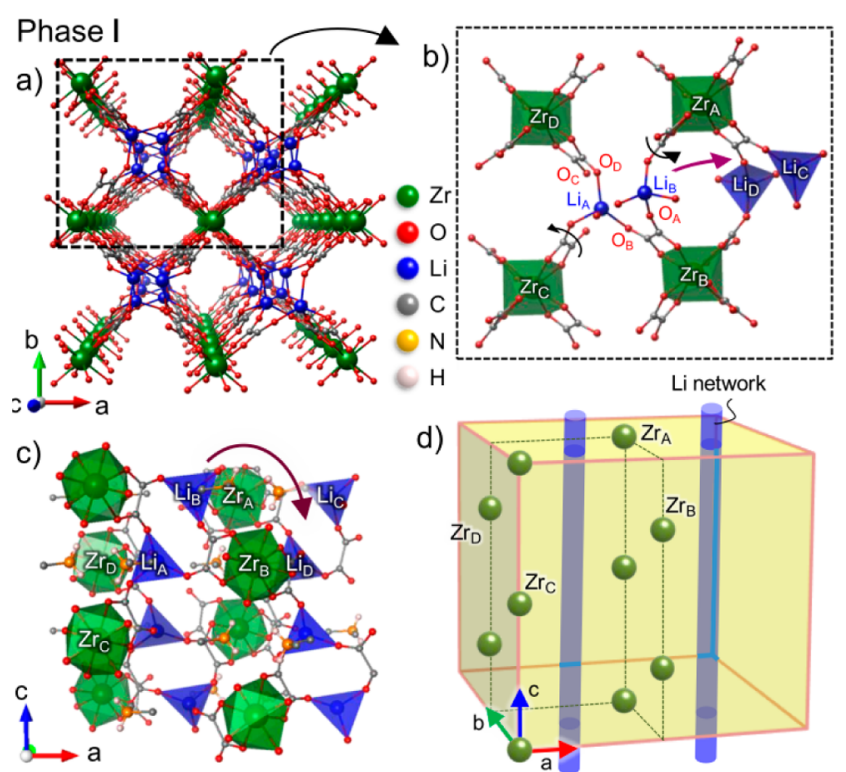

d)
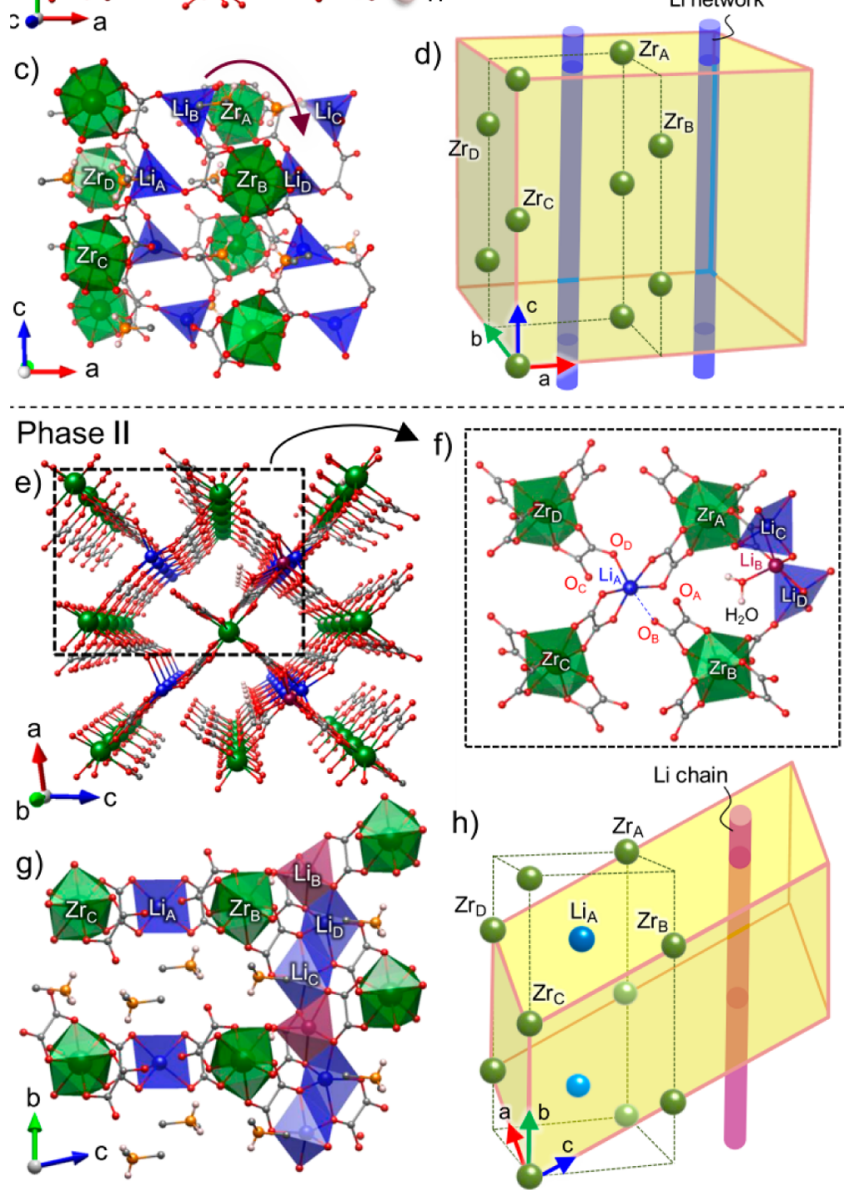

Figure 2. Topotactic hydration of phase I $(a-d)$ to form phase II $(e-h)$. $(\mathrm{a}, \mathrm{e})$ The square, 1-D channels are retained during the hydration reaction. The channels are filled with dimethylammonium (dma) cations, which are omitted for clarity (both are dense structures). (b,f) The topotactic conversion can be interpreted by rotation of $\mathrm{Zr}$ polyhedra $\left(\mathrm{Zr}_{\mathrm{A}}\right.$ and $\mathrm{Zr}_{\mathrm{C}}$, black arrows $)$, triggered by hydration of $\mathrm{Li}_{\mathrm{B}}$ and its movement into the gap between $\mathrm{Li}_{C}$ and $\mathrm{Li}_{\mathrm{D}}$. In phase II, the hydrated $\mathrm{Li}_{\mathrm{B}}$ is highlighted in red. $\mathrm{Li}_{\mathrm{A}}$ has long coordination with $\mathrm{O}_{\mathrm{D}}(2.32 \AA)$ and negligibly weak coordination with $\mathrm{O}_{\mathrm{B}}(2.50 \AA)$. $\mathrm{O}_{\mathrm{A}}$ and $\mathrm{O}_{\mathrm{C}}$ are noncoordinating $\mathrm{O}$-atoms. $(c, g)$ Side view of the channels. dma cations lie between two $\mathrm{Zr}$ polyhedra along the $c$ axis in I, and along the $b$ axis in II. $\mathrm{H}$-atoms on methyl groups are omitted for clarity. (d,h) Crystallographic orientation relationships. Unit cells (yellow) and cuboids formed by $\mathrm{Zr}$ polyhedral chains (black dotted line).

crystallographic relationship between the parent crystal and the hydrated phase is retained, as expected for topotactic reactions, which are known to be useful for synthesizing new materials that cannot be accessed by other methods. ${ }^{26}$ This is a new example in a dense $\mathrm{MOF}^{27}$

The direct structural transformation via a topotactic route is also supported by PXRD data (Figure S8), which show that the
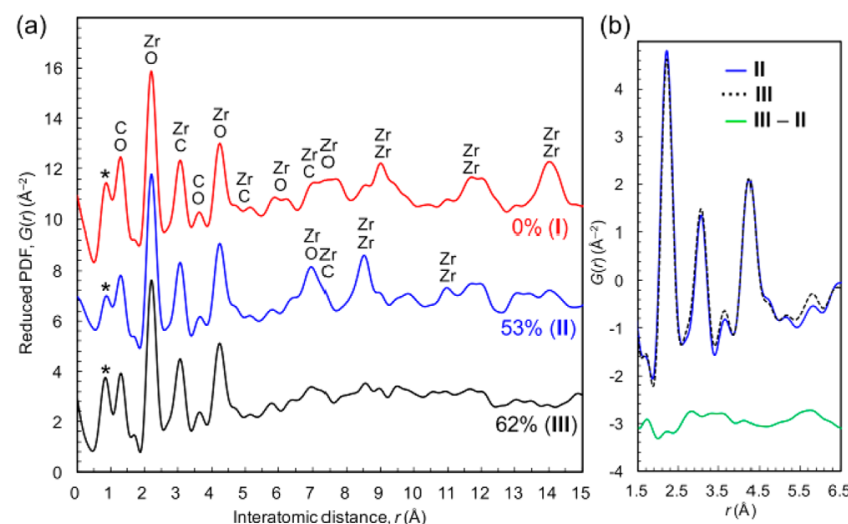

Figure 3. Pair distribution function analysis of phases I, II, and III. (a) Comparison of X-ray PDFs. The data are offset for clarity. The peaks around $0.9 \AA(*)$ are attributable mainly to termination errors caused by the Fourier transformation $\left(Q_{\max }=17.1 \AA^{-1}\right)$. (b) Difference of PDFs between II and III.

Bragg peaks of I decrease with the increase in peaks of II. The lattice parameters of both phases are constant during the hydration (Figure S9 and Table S2), indicating that this transition is first-order and abrupt rather than continuous. The formation energy from I with water vapor to II is calculated to be in the range of chemisorption $(-108 \mathrm{~kJ} / \mathrm{mol})$ by density functional theory (DFT) calculations; ${ }^{28}$ in other words, the transformation is energetically strongly favorable. The irreversible transformation to II is reasonable because the dehydration of II with retention of its framework structure requires only 113 $\mathrm{kJ} / \mathrm{mol}$, which is only $5 \mathrm{~kJ} / \mathrm{mol}$ larger than the formation energy of I from II (Table S3 and CIF files).

Because III is formed from twin domains that are present in II and sensitive to humidity, we have been unable to determine its crystal structure. However, since the transformation between II and III is reversible, we can assume that the connectivity is mostly retained. In light of this, we used pair distribution functions (PDFs) to analyze the local and middle-range order of III.

The PDFs (Figure 3) were obtained by analyzing the X-ray total scattering patterns of the samples sealed in glass capillaries under humidity control (Figure S10). For I and II, the PDFs were simulated from their crystal structures (Figure S11), and the peaks assigned to atomic pairs as shown in Figure 3a. The peaks in the range of $2-4.5 \AA$ represent the $\mathrm{Zr}(\text { ox })_{4}$ coordination units and are consistent in all three phases. The PDFs of I and II are different in the longer distance regions, reflecting their different crystal structures. The PDF of III is clearly very similar to that of II in the range $2-6.5 \AA$ (Figure $3 \mathrm{~b}$ ), indicating that the structure around the zirconium/oxalate unit is preserved. At longer distances, however, we see the loss of large peaks (e.g., $\mathrm{Zr}-\mathrm{Zr}$ pairs at $8.49 \AA$ ), suggesting that the long-range order is not as good in III. To accommodate four water molecules per $\mathrm{Zr}$ ion in III, the framework must expand without changing the overall connectivity, and the water molecules (probably extra-framework rather than coordinated) are placed in the expanded channel structure. This is consistent with our observation that the transformation between II and III is reversible.

Regarding the proton source, DFT calculations using the structure of II show that proton transport from the dma cations to the $\mathrm{O}$-atoms requires significant energy, e.g., transfer to the water molecules needs $220 \mathrm{~kJ} / \mathrm{mol}$, ruling out proton conduction involving the dma cations. Charge distribution analysis of II 
(Figures S12-S14) reveals that the coordinating water molecules contribute to the screening of cationic charge of $\mathrm{Li}_{\mathrm{B}}$ (Figure $2 \mathrm{f}$ ) by $28 \%$ (Figure S14), which in turn indicates partial deprotonation of the water molecules; namely, the water molecules coordinated to $\mathrm{Li}$ ions are considered to be the proton source. Though the coordinated water molecules $\mathrm{H}$-bond with oxalate molecules (Figure S15), II is not conductive, meaning that the protons do not transport through oxalate ions (e.g., intramolecular proton transport) ${ }^{29}$ as shown in Figure S16, and need additional water molecules as carriers.

The humidity-induced insulator-to-proton-conductor transition is a rare phenomenon. The layered system, hydrogen uranyl phosphate, and related materials show a gradual insulator-toproton-conductor transition by hydrate formation. ${ }^{15,17}$ The gradual feature is probably due to the amorphous structure of the anhydrous phase. MOFs, however, provide new opportunities, ${ }^{4}$ though the tendency of many MOFs to be unstable in the presence of moisture may lead us to expect them to be unlikely candidates for such behavior. However, a layered MOF, $\left(\mathrm{NH}_{4}\right)_{2}(\mathrm{adp})\left[\mathrm{Zn}_{2}(\mathrm{ox})_{3}\right] \cdot n \mathrm{H}_{2} \mathrm{O}(n=0,2$, and 3$)$, shows an abrupt insulator-to-proton-conductor transition with water uptake $(n=0-2)$ and a conductor-to-superprotonic conductor transition around $100 \% \mathrm{RH} .{ }^{19}$ Our material is three-dimensional and exhibits an abrupt transition at the middle $\mathrm{RH}$ range of 58\%, probably because of the dense crystalline nature of the insulating phase II, and its transition to another crystalline structure of the hydrate phase, III.

\section{ASSOCIATED CONTENT}

\section{(S Supporting Information}

Experimental details, impedance and crystal structure data, dynamic vapor sorption, X-ray total scattering and TGA data, PXRD analysis, single-crystal micro-FTIR, quantum chemistry calculations, and detailed analysis of the crystal structures. The Supporting Information is available free of charge on the ACS Publications website at DOI: $10.1021 /$ jacs.5b02777.

\section{AUTHOR INFORMATION}

\section{Corresponding Authors}

*tominaka.satoshi@nims.go.jp

*akc30@cam.ac.uk

\section{Notes}

The authors declare no competing financial interest.

\section{ACKNOWLEDGMENTS}

This work was supported by the European Research Council (ERC; AKC) and WPI-MANA from MEXT, Japan. F.-X.C. acknowledges the access of HPC resources from GENCI (grant i2015087069). We thank Micromeritics Japan for the help in the water vapor isotherm measurements, and Surface Measurement Systems and Nippon Science Core for the help in the dynamic water vapor sorption measurements.

\section{REFERENCES}

(1) Eddaoudi, M.; Kim, J.; Rosi, N.; Vodak, D.; Wachter, J.; O’Keeffe, M.; Yaghi, O. M. Science 2002, 295, 469.

(2) Halder, G. J.; Kepert, C. J.; Moubaraki, B.; Murray, K. S.; Cashion, J. D. Science 2002, 298, 1762.

(3) Serre, C.; Millange, F.; Thouvenot, C.; Nogues, M.; Marsolier, G.; Louer, D.; Férey, G. J. Am. Chem. Soc. 2002, 124, 13519.

(4) Cheetham, A. K.; Rao, C. N. R. Science 2007, 318, 58.

(5) Spencer, E. C.; Kiran, M. S. R. N.; Li, W.; Ramamurty, U.; Ross, N. L.; Cheetham, A. K. Angew. Chem., Int. Ed. 2014, 53, 5683.
(6) (a) Park, M. J.; Nedoma, A. J.; Geissler, P. L.; Balsara, N. P.; Jackson, A.; Cookson, D. Macromolecules 2008, 41, 2271. (b) Zhang, H.; Li, L.; Müller, M.; Zhu, X. M.; Rueda, J. J. H.; Rosenthal, M.; Ivanov, D. A. Adv. Mater. 2013, 25, 3543.

(7) Xu, W. Q.; Tosca, N. J.; McLennan, S. M.; Parise, J. B. Am. Mineral. 2009, 94, 1629.

(8) Kepert, C. J.; Hesek, D.; Beer, P. D.; Rosseinsky, M. J. Angew. Chem., Int. Ed. 1998, 37, 3158.

(9) Tominaka, S.; Cheetham, A. K. RSC Adv. 2014, 4, 54382.

(10) Tominaka, S.; Henke, S.; Cheetham, A. K. CrystEngComm 2013, 15, 9400 .

(11) Proton conductors: Solids, membranes and gels (materials and devices); Colomban, P., Ed.; Cambridge University Press: Cambridge, UK, 1992.

(12) (a) Hurd, J. A.; Vaidhyanathan, R.; Thangadurai, V.; Ratcliffe, C. I.; Moudrakovski, I. L.; Shimizu, G. K. H. Nat. Chem. 2009, 1, 705. (b) Yoon, M.; Suh, K.; Natarajan, S.; Kim, K. Angew. Chem., Int. Ed. 2013, 52, 2688. (c) Umeyama, D.; Horike, S.; Inukai, M.; Itakura, T.; Kitagawa, S. J. Am. Chem. Soc. 2012, 134, 12780. (d) Yamada, T.; Sadakiyo, M.; Kitagawa, H. J. Am. Chem. Soc. 2009, 131, 3144. (e) Ramaswamy, P.; Wong, N. E.; Shimizu, G. K. H. Chem. Soc. Rev. 2014, 43, 5913. (f) Bureekaew, S.; Horike, S.; Higuchi, M.; Mizuno, M.; Kawamura, T.; Tanaka, D.; Yanai, N.; Kitagawa, S. Nat. Mater. 2009, 8, 831.

(13) (a) Fuma, Y.; Ebihara, M.; Kutsumizu, S.; Kawamura, T. J. Am. Chem. Soc. 2004, 126, 12238. (b) Iguchi, H.; Takaishi, S.; Miyasaka, H.; Yamashita, M.; Matsuzaki, H.; Okamoto, H.; Tanaka, H.; Kuroda, S. Angew. Chem., Int. Ed. 2010, 49, 552.

(14) Niel, V.; Thompson, A. L.; Munoz, M. C.; Galet, A.; Goeta, A. S. E.; Real, J. A. Angew. Chem., Int. Ed. 2003, 42, 3760.

(15) Colomban, P.; Novak, A. In Proton conductors: Solids, membranes and gels (materials and devices); Colomban, P., Ed.; Cambridge University Press: Cambridge, UK, 1992; pp 38-60.

(16) Sadakiyo, M.; Yamada, T.; Kitagawa, H. J. Am. Chem. Soc. 2009, 131, 9906.

(17) Barboux, P.; Morineau, R.; Livage, J. Solid State Ionics 1988, 27, 221.

(18) Okawa, H.; Sadakiyo, M.; Yamada, T.; Maesato, M.; Ohba, M.; Kitagawa, H. J. Am. Chem. Soc. 2013, 135, 2256.

(19) Sadakiyo, M.; Yamada, T.; Honda, K.; Matsui, H.; Kitagawa, H. J. Am. Chem. Soc. 2014, 136, 7701.

(20) Onishi, S.; Ohmori, T.; Ohkubo, T.; Noguchi, H.; Di, L.; Hanzawa, Y.; Kanoh, H.; Kaneko, K. Appl. Surf. Sci. 2002, 196, 81.

(21) Giron, D.; Goldbronn, C.; Mutz, M.; Pfeffer, S.; Piechon, P.; Schwab, P. J. Therm. Anal. Calorim. 2002, 68, 453.

(22) Panda, T.; Kundu, T.; Banerjee, R. Chem. Commun. 2013, 49, 6197.

(23) Spek, A. L. Acta Crystallogr., Sect. D 2009, 65, 148.

(24) Cussen, E. J.; Claridge, J. B.; Rosseinsky, M. J.; Kepert, C. J. J. Am. Chem. Soc. 2002, 124, 9574.

(25) Cheetham, A. K.; Rao, C. N. R.; Feller, R. K. Chem. Commun. 2006, 4780.

(26) (a) Hayward, M. A.; Cussen, E. J.; Claridge, J. B.; Bieringer, M.; Rosseinsky, M. J.; Kiely, C. J.; Blundell, S. J.; Marshall, I. M.; Pratt, F. L. Science 2002, 295, 1882. (b) Tsujimoto, Y.; Tassel, C.; Hayashi, N.; Watanabe, T.; Kageyama, H.; Yoshimura, K.; Takano, M.; Ceretti, M.; Ritter, C.; Paulus, W. Nature 2007, 450, 1062. (c) Tominaka, S.; Yoshikawa, H.; Matsushita, Y.; Cheetham, A. K. Mater. Horiz. 2014, 1, 106. (d) Tominaka, S. Inorg. Chem. 2012, 51, 10136.

(27) Kole, G. K.; Vittal, J. J. Chem. Soc. Rev. 2013, 42, 1755.

(28) (a) Cliffe, M. J.; Wan, W.; Zou, X. D.; Chater, P. A.; Kleppe, A. K.; Tucker, M. G.; Wilhelm, H.; Funnell, N. P.; Coudert, F. X.; Goodwin, A. L. Nat. Commun. 2014, 5, 4176. (b) Ortiz, A. U.; Boutin, A.; Gagnon, K. J.; Clearfield, A.; Coudert, F. X. J. Am. Chem. Soc. 2014, 136, 11540.

(29) Bosch, E.; Moreno, M.; Lluch, J. M. Can. J. Chem. 1992, 70, 100. 